\title{
ABORDAGEM TEMÁTICA E CONTEXTOS DE VIDA EM UMA PRÁTICA EDUCATIVA EM CIÊNCIAS E BIOLOGIA NA EJA
}

\section{Thematic approach and contexts of life in a science and biology educative practice in EJA}

\author{
Adelson Fernandes Moreira ${ }^{1}$ \\ Leonardo Augusto Gonçalves Ferreira ${ }^{2}$
}

\begin{abstract}
Resumo: Neste artigo, analisamos depoimentos de educandos acerca de suas vivências em uma prática educativa no ensino de Ciências e Biologia na Educação de Jovens e Adultos, nomeada de Seminários Interativos. Os dados obtidos em vídeo foram categorizados confrontando-se elementos significativos dos depoimentos com os objetivos da prática em questão e as observações do educador na sua interação com os educandos durante o processo. Esse educador coordenou o desenvolvimento dos seminários e é um dos responsáveis pela pesquisa. Os depoimentos representativos das diferentes visões orientaram a realização de um grupo focal com o objetivo de detalhar e confirmar a representatividade das categorias construídas. Os depoimentos dos educandos indicam uma aproximação entre conhecimento científico e realidade. Entretanto, essas não foram as únicas contribuições da prática, que também possibilitou o desenvolvimento de habilidades de comunicação e interpretação e atitudes relativas a negociação e convivência coletiva.
\end{abstract}

Palavras-chave: Educação de jovens e adultos. Prática educativa. Educação científica.

\begin{abstract}
In this article we analyze student's speeches about its experiences in an educative science and biology practice in Adult and Young Education nominated Interactive Seminaries. These speeches were video recorded, observed and categorized, detaching relevant elements referring to objectives of practice in question and to educator observation of the student's interaction during the process. This educator co-ordinated the seminaries development and is one of the researchers. The representative speech of the different visions had guided the accomplishment of a focal group with the objective to detail and to confirm the categories constructed. The students' speechs indicate relations between scientific knowledge and student's life contexts. Moreover, the Interactive Seminaries also made possible the development of communication and interpretation abilities and negotiation and collective relationship attitudes.
\end{abstract}

Keywords: Young and adults education. Educative practice. Scientific education.

\footnotetext{
${ }^{1}$ Graduado em Física, doutorado em Educação. Professor Colaborador, Mestrado em Educação Tecnológica, Centro Federal de Educação Tecnológica de Minas Gerais (CEFET-MG). Belo Horizonte, MG, Brasil. $<$ adelson@deii.cefetmg.br>

${ }^{2}$ Graduado em Biologia, mestrado em Educação Tecnológica. Pesquisador, CEFET-MG. Belo Horizonte, MG, Brasil.<prof.leobio@gmail.com>

${ }^{1}$ Rua Botelhos, 28

Bonfim - Belo Horizonte, MG

31.210-200 
Moreira, A. F.; Ferreira, L. A. G.

\section{Introdução}

Neste artigo apresentamos resultados de um estudo sobre as percepções de educandos acerca de uma prática educativa em Ciências e Biologia na Educação de Jovens e Adultos (EJA), os Seminários Interativos.

Os Seminários Interativos, discutidos a partir da percepção dos educandos, se fundamentam na necessidade de seconstruírem, para a EJA, ambientes de aprendizagem que respondam aos desafios próprios dessa modalidade de ensino.

As percepções dos educandos foram levantadas de duas formas distintas: depoimentos espontâneos, dados após a apresentação dos Seminários, e grupos focais, cujo roteiro de discussão foi preparado com base no conteúdo daqueles depoimentos. Os dados obtidos com esses dois processos foram confrontados com um detalhado diário de bordo, elaborado pelo educador que acompanhou esses estudantes e que é um dos autores do trabalho.

A análise dos dados aponta para as possibilidades da prática educativa desenvolvida, especialmente, no diálogo entre os conteúdos conceituais de Biologia e os contextos de vida dos educandos, assim como o desenvolvimento de habilidades de comunicação e interpretação e de atitudes relacionadas à negociação e convivência coletiva.

\section{Por uma prática educativa própria da EJA}

A educação de jovens e adultos requer uma proposta diferenciada, vinculada ao contexto social vivido pelos educandos. Di Pierro, Joia e Ribeiro (2001) salientam que a EJA tem sua origem significativa no início do século passado, a partir de movimentos populares.

Abrigadas freqüentemente em igrejas, associações de moradores, organizações de base local e outros espaços comunitários, essas iniciativas experimentaram propostas de alfabetização e pósalfabetização de adultos que se nutriram no paradigma da educação popular, impulsionando a busca de uma adequação de metodologias e conteúdos às características etárias e de classe dos educandos. (DI PIERRO; JOIA; RIBEIRO, 2001, p. 61)

A escola, para o público da EJA, considerando sua origem, deve compreender os sujeitos envolvidos com um papel ativo em seu desenvolvimento sociocultural. São homens, mulheres, negros, brancos, adultos, adolescentes, trabalhadores, trabalhadoras, enfim, estudantes e professores, seres humanos concretos, sujeitos sociais e históricos que são afetados por fatores socioeconômicos, espaciais, geracionais, étnicos e de gênero, contribuindo para a produção de desníveis educativos (HADDAD; DI PIERRO, 2000).

Logo, encontramos, no espaço da EJA, a conjunção de trajetórias escolares diferenciadas, uma vez que se constitui em

[...] oportunidade educativa para um largo segmento da população, com três trajetórias escolares básicas: para os que iniciam a escolarida- 
de já na condição de adultos trabalhadores; para adolescentes e adultos jovens que ingressaram na escola regular e a abandonaram há algum tempo, freqüentemente motivados pelo ingresso no trabalho ou em razão de movimentos migratórios e, finalmente, para adolescentes que ingressaram e cursaram recentemente a escola regular, mas acumularam aí grandes defasagens entre a idade e a série cursada. (DI PIERRO; JOIA; RIBEIRO, 2001, p. 65)

Nesse ponto, ressaltamos que a melhoria das condições de acesso ao ensino regular ampliou as oportunidades de escolarização dos mais jovens. No entanto, esse aumento também pode ser percebido na EJA, que tem recebido um número cada vez maior de jovens excluídos do ensino regular, gerando novas demandas, inclusive no que se refere às práticas pedagógicas (HADDAD; DI PIERRO, 2000). Carrano (2007), referindo-se aos jovens na EJA e à necessidade de uma escola formadora e inclusiva capaz de reorganizar saberes, espaços e tempos, afirma que

A escola espera alunos e o que chega são sujeitos com múltiplas trajetórias e experiências de vivência do mundo. São jovens que, em sua maioria, estão aprisionados no espaço e no tempo - presos em seus bairros e incapacitados para produzirem projetos de futuro. Sujeitos que, por diferentes razões, têm pouca experiência de circulação pela cidade e se beneficiam pouco ou quase nada das poucas atividades e redes culturais públicas ofertadas em espaços centrais e mercantilizados das cidades. Jovens que vivem em bairros violentados, onde a violência é a chave organizadora da experiência pública e da resolução de conflitos. (CARRANO, 2007, p. 10)

O caráter formador e reflexivo da educação deste jovem e do adulto se faz por meio de práticas educativas capazes de partirem da realidade do educando e de irem além dela, possibilitando, ao estudante, uma tomada de consciência de si próprio. Assim como destaca Carrano (2007), é preciso (re)conhecer a trajetória desses sujeitos, compreendendo contextos não escolares, cotidianos e históricos mais amplos em que estão imersos, a fim de acrescentar elementos capazes de promoverem a aprendizagem escolar. O ensino deve agregar aspectos motivacionais, valorizar o sonho, o desejo de mudança, respeitando e reconhecendo os saberes construídos ao longo da vida. A educação deve permitir a esse educando viver com dignidade, tendo garantida sua condição de cidadão. A escola erra quando não considera estas questões e funda o processo educativo na transmissão e assimilação de conteúdos principalmente conceituais, predeterminados, transmitidos através de ritmos médios, com foco no produto e pouca atenção às diferenças existentes entre os educandos. Procedendo dessa forma, desconsidera o indivíduo real e social que está diante desta escola em busca de uma ressignificação do saber para a vida. Como questiona Dayrell (1996), a escola

Reduz os sujeitos a alunos, apreendidos, sobretudo pela dimensão cognitiva. O conhecimento é visto como produto, sendo enfatizados os 
Moreira, A. F.; Ferreira, L. A. G.

resultados da aprendizagem e não o processo. Essa perspectiva implementa a homogeneidade de conteúdos, ritmos e estratégias, e não a diversidade. Explica-se assim a forma como a escola organiza seus tempos, espaços e ritmos bem como o seu fracasso. Afinal de contas, não podemos esquecer - o que essa lógica esquece - que os alunos chegam à escola marcados pela diversidade, reflexo dos desenvolvimentos cognitivo, afetivo e social, evidentemente desiguais, em virtude da quantidade e qualidade de suas experiências e relações sociais, prévias e paralelas á escola. O tratamento uniforme dado pela escola só vem consagrar a desigualdade e as injustiças das origens sociais dos alunos. (DAYRELL, 1996, p. 140)

Que conceito de educação científica dialoga com o desafio de se desenvolverem práticas educativas identificadas com as necessidades da EJA? Delimitamos o conceito de educação científica com base em trabalhos do campo de pesquisa da educação em Ciências. A delimitação desse conceito, em um diálogo permanente com nossa experiência educativa, se faz também a partir de princípios pedagógicos propostos por Paulo Freire, em sua discussão sobre o oprimido, sobre prática educativa e sobre autonomia. Buscamos nos referenciar nas contribuições teóricas acerca da educação científica, a fim de tornar possível o diálogo entre a prática educativa em questão e o ensino de Ciências e Biologia. Em Paulo Freire (2002, 2003), refletimos sobre as condições desse educando jovem e adulto e o sentido atribuído por ele à prática educativa em função do contexto de vida em que se insere.

A educação, para esse público jovem e adulto, não deve ser neutra, apolítica e isenta das responsabilidades sociais e de humanização. Trata-se de uma educação dialógica, em que deve haver "amor e humildade" (FREIRE, 2002, p. 80). O diálogo e a dialogicidade baseados nessas condições são essências em uma educação como prática da liberdade, ancorada nos princípios da educação popular. Liberdade que requer incessante busca, compreendida como uma conquista, e não uma doação (FREIRE, 2002, p. 34). Uma liberdade que possibilite a criação, a admiração e a capacidade de aventurar-se (FREIRE, 2002, p. 55).

O diálogo é uma relação de encontro interativo e reflexivo entre os homens, mediados pelos artefatos do mundo, para "ser mais" (FREIRE, 2002, p. 82), ou seja, reconhecer o outro como sujeito, como ser humano, aceitando-o como é, ultrapassando a troca de conceitos e aproximando-se da troca de sentidos e significados que alimentam a consciência.

Paulo Freire (2002) também nos mostra que a relação dialógica como fenômeno humano se faz pela ação e a reflexão, que se dão simultaneamente como dimensões solidárias que configuram o humano, conforme suas palavras: "não é no silêncio que os homens se fazem, mas na palavra, no trabalho, na ação-reflexão" (FREIRE, 2002, p. 78).

O autor salienta que, nessa ação e reflexão, emerge a ação criadora do humano ligada a sua práxis, uma vez que

[...] os homens que, através de sua ação sobre o mundo, criam o domínio da cultura e da história, está em que somente estes são seres da práxis. Práxis que, sendo reflexão e ação verdadeiramente transformadora da realidade, é fonte de conhecimento reflexivo e criação. [...] os 
Abordagem temática e contextos de vida ...

homens, simultaneamente, criam a história e se fazem seres históricosociais. (FREIRE, 2002, p. 92)

Portanto, ensinar e aprender Ciências não devem estar pautados unicamente em uma aprendizagem de conceitos e metodologias científicas, mas também na consideração de uma perspectiva mais ampla, que valorize os saberes prévios, a partir dos quais se deve buscar a construção de um conhecimento científico, capaz de proporcionar ao ser humano uma maior interferência e interação com o mundo (LABURÚ, 2005). Carrano (2007) ressalta a necessidade de abandonarmos toda pretensão de elaboração de conteúdos únicos e arquiteturas curriculares rigidamente estabelecidas.

Tais princípios compõem uma visão de Educação Científica de Jovens e Adultos vinculada a um currículo capaz de relacionar Ciência e Sociedade, incluindo a prática social dos educandos - considerando o contexto socioeconômico, articulando conhecimento científico e realidade de maneira crítica, contribuindo para a formação de um sujeito capaz de se inserir em processos de transformação dessa realidade (SANTOS; SCHNETZLER, 1997 apud TEIXEIRA, 2003).

A relação entre Ciência e Sociedade, no desenvolvimento curricular, deve considerar a ética que orienta as produções científicas, articulando ciência, tecnologia e suas dimensões humanas (SANTOS, 2007).

Todos esses princípios constituem uma prática educativa comprometida com a formação de um indivíduo cientificamente letrado, isto é, capaz de fazer uso de conceitos e habilidades aprendidos no contexto de uma educação científica, na compreensão crítica de sua realidade (PRATA; MARTINS, 2005). Paulo Freire (2003) afirma que, para o desenvolvimento da autonomia do educando, faz-se necessária uma pedagogia permeada por ética, respeito e dignidade, articulada a uma ação vigilante quanto às práticas desumanizadoras.

Assume-se, como desafio, a constituição de práticas educativas que contemplem as necessidades próprias desse público jovem e adulto. Para além do acesso à escolarização, é fundamental refletir sobre sua forma e conteúdo, considerando as especificidades dessa modalidade de ensino. Carrano (2007) argumenta que, nos espaços da EJA, os sujeitos são múltiplos e, ainda que existam sujeitos com perfis similares, é preciso estar atento para as trajetórias de vida que sempre são singulares e portadoras de potencialidades que podem não se revelar de imediato.

Isso implica a constante formação do educador que, para Paulo Freire (2003), realiza uma reflexão crítica sobre sua prática, repensando e aprimorando a próxima prática. Essa relação reflexiva torna-se própria e necessária na constituição de uma prática transformadora, assim,

O desafio do conhecimento na EJA não pode ser circunscrito àquilo que alunos e alunas devem aprender, ele também é provocação para que educadores e educadoras aprofundem seus conhecimentos - suas compreensões - sobre seus sujeitos da aprendizagem. (CARRANO, 2007, p. 10)

Nesse sentido, a práxis do educador se coloca para além de avaliações e ensino de conteúdos, coloca-se diante da interação educador e educando num processo de aprendizado 
recíproco e contínuo, através de uma metodologia que seja capaz de oportunizar ao educando uma visão crítica do mundo, oferecendo significado e atingindo a todos.

O ensino, nessa perspectiva, não é um processo unidirecional, centrado no educador e pautado na transmissão dos saberes; trata-se de uma tarefa que não se baliza em treinamentos e transferência de conhecimentos, mas, sim, um processo capaz de criar as possibilidades para a sua produção ou a sua construção. Nas palavras de Freire:

Uma das tarefas essenciais da escola, como centro de produção sistemática de conhecimento, é trabalhar criticamente a inteligibilidade das coisas e dos fatos e a sua comunicabilidade. [...] É preciso por outro lado e, sobretudo, que o educando vá assumindo o papel de sujeito da produção de sua inteligência do mundo e não apenas o de recebedor da que lhe seja transferida pelo professor. (FREIRE, 2003, p. 124)

Os educandos devem estar inseridos em um ambiente de aprendizagem que lhes permita,

[...] acessar um amplo leque de conhecimentos e informações. Com base nisso lhes foi possível, se não criar, no mínimo ampliar a identificação de si mesmos como cidadãos e a compreensão de seu papel enquanto sujeitos, tanto de direitos quanto de deveres. (DAYRELL, 1989 apud SANTOS, 2003, p. 111)

Propomos uma prática educativa que, por um lado, é calcada em conceitos e fundamentos sistematizados e, por outro, deve ser contextualizada e vinculada à vida do educando. Hansen e Pinheiro (2005), nesse sentido, esclarecem que

Atualmente é difundida a opinião de que o ensino de ciências naturais não deve se resumir a simples memorização de idéias, mas que deve ser uma atividade ativa, onde o aluno possa incorporar procedimentos e valores relacionados à prática científica que contribuam para seu desenvolvimento como cidadão crítico na sociedade. (HANSEN; PINHEIRO, 2005, p. 2)

Em sua pedagogia da autonomia, aprendemos, com Paulo Freire (2003), a inconclusão do ser, sua necessária inserção na sociedade por meio de uma prática educativa que não desvincule o saber da ciência da prática social. Em sua pedagogia do oprimido, aprendemos, com Paulo Freire (2002), a complexidade de se superar a situação de opressão na qual se encontra o oprimido e as possibilidades abertas pela presença do outro e pela sua palavra, quando essa significa pronunciar o mundo, na busca de transformá-lo.

A inconclusão do ser, a inserção dos saberes científicos na prática social, a presença do outro e de sua palavra, a pronunciar e transformar o mundo, são elementos da pedagogia freireana que qualificam nossa compreensão de educação científica. Essa compreensão qualificada passa: pelo resgate do conhecimento prévio do educando, pela busca de um aprendiza- 
Abordagem temática e contextos de vida ...

do de conhecimentos científicos a partir de temas que se relacionem com os contextos de vida dos educandos, que sejam objeto de uma pesquisa realizada coletivamente e que confira, especialmente ao educando, a possibilidade de compartilhar o que pesquisou e aprendeu.

Uma educação dialógica, cuja ênfase não se coloca na transmissão de conteúdos, mas na formação de um sujeito capaz de compreender e atuar criticamente na sociedade, se consolida como fundamento, em especial para os educandos da EJA que trazem consigo marcas de uma escolarização fragilizada e descolada de seu papel social.

Dentro dessa perspectiva de educação científica para a EJA, desenvolve-se uma prática educativa chamada de Seminários Interativos. Os seminários interativos buscam compor um cenário de práticas educativas capazes de dialogar com essa perspectiva de não- desumanização do sujeito, onde os conteúdos sistematizados não têm um fim em si mesmos. Buscamos considerar o educando em sua inteireza, em suas emoções carregadas de sentido, reconhecendo a autonomia e capacidade desse educando em se apropriar dos saberes sistematizados sob uma lente crítica da realidade que o cerca, a fim de modificá-la.

No diálogo com essa percepção de educação científica para jovens e adultos, adotamos uma proposta educativa que se apoia na abordagem temática, assim definida como

Perspectiva curricular cuja lógica de organização é estruturada com base em temas, com os quais são selecionados os conteúdos de ensino das disciplinas. Nessa abordagem, a conceituação científica da programação é subordinada ao tema. (DELIZOICOV; ANGOTTI; PERNAMBUCO, 2002 apud AULER; DALMOLIN; FENALTI, 2009, p. 70)

A abordagem temática que orienta os seminários interativos está articulada a uma perspectiva de ensino de ciências para jovens e adultos. Segundo Souza (2005), a proposta busca ser capaz de conduzir os educandos a uma visão mais ampla de ciência, promovendo maior compreensão das manifestações culturais, sociais e científicas na sociedade.

\section{Seminários Interativos}

Os Seminários Interativos têm como objetivo proporcionar uma articulação entre os conteúdos do ensino de Ciências e Biologia e a prática social dos educandos, dentro de uma abordagem que valorize a construção dos conhecimentos. Pretende-se um trabalho com os conteúdos escolares contextualizados, centrados no estudo de temas contemporâneos, no trabalho cooperativo, na utilização de tecnologias de informação e comunicação, bem como na apresentação pública dos resultados, buscando, enfim, a promoção de uma experiência significativa para os estudantes.

Auler, Dalmolin e Fenalti (2009, p. 75) enfatizam que:

O "mundo da vida" adentra no "mundo da escola", nas configurações curriculares, através do que este educador denominou de temas geradores. [...] Estes carregam, para dentro da escola, a cultura, as situações problemáticas vividas, os desafios enfrentados pela comunidade 
Moreira, A. F.; Ferreira, L. A. G.

local. O mundo vivido, os problemas e as contradições nele presentes passam a ser o ponto de partida.

Respeitando as devidas delimitações conceituais, apontamos que a condição potencial de ser o tema gerador nos Seminários Interativos diferencia-se do significado do adjetivo gerador utilizado por Freire (2002), especialmente quando se leva em conta a forma como Freire propõe a constituição dos temas.

A deflagração desse projeto de ensino ocorre a partir de um conjunto de temas escolhidos e propostos pelo educador (Quadro 1). Esses temas são referenciados nos conteúdos conceituais básicos previstos para a etapa de EJA na qual a turma está inserida. São também fruto de um diálogo permanente, ao longo de anos, com os educandos jovens e adultos, que conduziu a proposições com o potencial de articular conteúdos conceituais e contextos de vida.

Quadro 1. Temas propostos - 2007.

\begin{tabular}{|c|c|c|c|}
\hline $\begin{array}{l}3^{\circ} \text { período do Ensino } \\
\text { Fundamental }\end{array}$ & $\begin{array}{l}4^{\circ} \text { período do Ensino } \\
\text { Fundamental }\end{array}$ & $\begin{array}{c}1^{\circ} \text { período do Ensino Médio } \\
1 \text { e } 2\end{array}$ & $\begin{array}{c}2^{\circ} \text { período do Ensino } \\
\text { Médio }\end{array}$ \\
\hline $\begin{array}{l}\text { Importância da higiene } \\
\text { - higiene corpórea e } \\
\text { social }\end{array}$ & $\begin{array}{l}\text { Reciclando vidas (poluição, } \\
\text { lixo, saúde e reciclagem). }\end{array}$ & $\begin{array}{l}\text { O uso de bebidas alcoólicas e } \\
\text { seus efeitos sociais e } \\
\text { pessoais }\end{array}$ & $\begin{array}{l}\text { Síndrome de Down - } \\
\text { conceitos e preconceitos }\end{array}$ \\
\hline $\begin{array}{l}\text { Levando uma vida } \\
\text { saudável - alimentos, } \\
\text { dietas e doenças } \\
\text { relacionadas }\end{array}$ & A química nos alimentos & Doce sem doce - diabetes & $\begin{array}{l}\text { Doar sangue, doar vida, e } \\
\text { hemofilia }\end{array}$ \\
\hline Transplantando vida & $\begin{array}{l}\text { Efeito estufa, camada de } \\
\text { ozônio e aquecimento } \\
\text { global }\end{array}$ & $\begin{array}{l}\text { Fumando o câncer - } \\
\text { tabagismo e câncer de pulmão }\end{array}$ & $\begin{array}{l}\text { Câncer de mama, } \\
\text { enfrentando os conceitos e } \\
\text { os preconceitos }\end{array}$ \\
\hline $\begin{array}{l}\text { Prestando os primeiros } \\
\text { socorros }\end{array}$ & Pura energia & $\begin{array}{l}\text { Menopausa: uma nova fase } \\
\text { com qualidade de vida }\end{array}$ & $\begin{array}{l}\text { No fundo dos teus olhos - } \\
\text { daltonismo }\end{array}$ \\
\hline \multirow{2}{*}{$\begin{array}{l}\text { Saúde da pele } \\
\text { Trabalhando e com } \\
\text { saúde (Saúde no } \\
\text { Trabalho) }\end{array}$} & $\begin{array}{l}\text { A Ciência e as guerras do } \\
\text { século }\end{array}$ & $\begin{array}{l}\text { Inimigo silencioso - } \\
\text { hipertensão arterial }\end{array}$ & $\begin{array}{l}\text { Teste do pezinho; } \\
\text { fenilcetonúria e } \\
\text { eritroblastose fetal }\end{array}$ \\
\hline & & $\begin{array}{l}\text { O baú de ossos - osteoporose } \\
\text { e reumatismos - Cuidados } \\
\text { com os ossos desde a } \\
\text { infância }\end{array}$ & $\begin{array}{l}\text { Clonagem humana - Projeto } \\
\text { Genoma Humano e ética }\end{array}$ \\
\hline
\end{tabular}

A apresentação de cada tema inicia um processo de problematização inicial e levantamento dos conhecimentos prévios dos educandos que fundamentam um roteiro de pesquisa.

O projeto é estruturado cooperativamente a partir de: elaboração de um cronograma de ações, organização dos grupos de trabalho, antecipação do resultado esperado da pesquisa sobre cada temática, e discussão dos critérios de avaliação durante todo o processo. 
Abordagem temática e contextos de vida ...

As ações que culminam nos Seminários Interativos envolvem o levantamento bibliográfico das informações acerca das temáticas, o tratamento e a problematização dos dados coletados preliminarmente. As informações coletadas e discutidas são selecionadas e utilizadas na elaboração de um relatório final, que obedece a critérios previamente definidos com os grupos de trabalho.

Ao término da pesquisa bibliográfica, os estudantes iniciam o período da estruturação da apresentação dos projetos desenvolvidos. Neste momento, possuem autonomia para decidirem qual a melhor forma de apresentá-los, podendo, inclusive, fazer uso de recursos para apresentações multimídia. A apresentação, em geral expositiva, conta com a participação de todos os componentes do grupo e pode ser acompanhada de recursos externos, sejam eles materiais ou por meio da participação de profissionais que trabalham com os temas investigados. O período de construção dos Seminários é de fevereiro - quando se apresentam e se problematizam os temas - até outubro, quando o último Seminário é apresentado.

Os Seminários Interativos são geralmente apresentados para um grupo maior de estudantes interessados e membros da comunidade educativa, compondo um espaço ampliado de discussão e construção cooperativa dos significados sobre as temáticas. Após o período de apresentações, são promovidos encontros para revisões conceituais sobre os temas desenvolvidos nos Seminários. As elaborações realizadas durante todo o projeto, bem como aquelas concebidas durante o processo de revisão conceitual, são abordadas em uma avaliação realizada, geralmente, em dupla, a fim de permitir também, nesse momento, uma discussão cooperativa quanto às questões propostas.

\section{Materiais e métodos: levantamento das percepções}

As percepções dos educandos jovens e adultos foram levantadas mediante a coleta de depoimentos espontâneos dos participantes do grupo responsável pelo Seminário do dia, após a sua apresentação. A obtenção desses depoimentos objetivou, inicialmente, registrar o sentimento dos educandos acerca da experiência com os Seminários Interativos. Perguntou-se qual a importância daquele trabalho para o educando. As respostas eram dadas de maneira espontânea, podendo o educando, inclusive, não responder, caso não o desejasse.

Esse registro seria utilizado na deflagração dos Seminários, em anos seguintes, como forma de incentivar o engajamento de novos educandos na proposta. Foram coletados 75 depoimentos, registrados em vídeo, cuja observação sistemática foi gerando categorias que articulam: elementos significativos destacados das falas, os objetivos da prática educativa em questão, e as percepções do educador pesquisador construídas ao longo da orientação dos grupos. Esse processo levou à escolha de 25 depoimentos representativos de 7 categorias.

Em um segundo momento, a representatividade desses depoimentos foi problematizada com o segundo autor. Essa discussão orientou nova observação dos 75 depoimentos com o objetivo de verificar se as categorias propostas abarcavam o conjunto das mensagens proferidas pelos educandos, ou se seria necessário elaborar novas categorias. Essa etapa resultou em pequenas alterações no título das categorias.

A categorização desses depoimentos seguiu uma orientação que transcende o sentido literal do enunciado, especialmente a partir dos registros feitos no diário de bordo pelo educa- 
dor que acompanhou os grupos e analisou, em primeira mão, os depoimentos. Indica uma tentativa de identificar as percepções dos estudantes acerca dos Seminários Interativos, conforme o diagrama 1. Os depoimentos representativos das categorias foram tomados como referência para a elaboração de um roteiro de questões a serem discutidas em um grupo focal, também constituído de forma espontânea com um representante de cada grupo.

Grupo focal é uma estratégia de entrevista capaz de fornecer dados a partir da percepção coletiva de um processo. Segundo Powell et al. (apud GIBBS, 1997), é formado por indivíduos agrupados pelos pesquisadores a fim de discutirem e comentarem uma experiência. Assim, são enfatizadas, pelo pesquisador, as relações existentes entre os integrantes do grupo, e não apenas na resposta objetiva de algum integrante. Cabe ao pesquisador encontrar estratégias eficientes para o registro acerca da multiplicidade de informações que poderão se destacar durante as discussões. Em um grupo focal, os dados são expressos não apenas em ideias e palavras, mas também em expressões e gestos que ratificam o diálogo em debate (MENEZES, 2003; KIND, 2004).

Nesse contexto, o grupo focal foi a estratégia capaz de permitir a produção de uma segunda base de dados para triangulação, assim como o distanciamento necessário da experiência também vivida pelo educador. Ainda assim, no grupo focal, poderiam ser refletidas as percepções gerais e específicas dos estudantes durante o percurso da prática, considerando a dimensão de um projeto longo e com várias vertentes de análise. As questões que nortearam a discussão do grupo focal procuravam, especialmente: objetivar o sentimento de aprendizado manifestado nos depoimentos, aferir a articulação entre conteúdos conceituais e os contextos de vida dos educandos, e oportunizar uma avaliação sobre a importância dos Seminários.

Foram selecionadas duas turmas para a realização do grupo focal, uma do Ensino Fundamental e outra do Ensino Médio. O ' 3 ' período do Ensino Fundamental', de acordo com a proposta curricular da escola, seria a turma concluinte do Ensino Fundamental, que vivenciava a prática pela primeira vez em seu currículo de Ciências. A outra turma seria o ' 2 ' período do Ensino Médio', concluinte do Ensino Médio, mais experiente com a prática educativa em questão.

Em cada grupo, foi feito um convite a fim de selecionar um estudante que pudesse colaborar com as discussões do grupo focal. Os estudantes escolhidos pelos grupos, de forma espontânea, normalmente eram aqueles mais engajados e envolvidos no processo. Assim, o grupo focal elaborado nas turmas era composto por seis estudantes, que poderiam compartilhar e discutir experiências vivenciadas em seus grupos de trabalho em um instante comum.

Nos momentos que antecederam a realização do grupo focal, buscou-se orientar as turmas quanto: à importância das discussões, a organização do grupo focal, o registro em áudio e vídeo, e a sensibilização da turma. Esta ocorreu por meio da reapresentação de três vídeos contendo depoimentos dos estudantes da turma acerca da experiência vivida com os Seminários.

O grupo focal foi desenvolvido durante duas aulas geminadas de quarenta e cinco minutos cada. Além do grupo de estudantes selecionados para a pesquisa, cujo acompanhamento seria dado diretamente pelo educador, e o registro feito em áudio e vídeo, foram elaborados outros cinco agrupamentos, que continham representantes de todos os grupos que apresentaram os Seminários. Para esses foi desenvolvido um roteiro básico de questões, que buscava apreender o contexto e os objetivos da prática educativa, envolvendo, em sua estrutu- 
ra, tanto perguntas sobre o sentido pessoal atribuído à experiência como outras mais abrangentes e de caráter conceitual. Esse registro seria utilizado posteriormente, a fim de ser confrontado com os dados obtidos pelo grupo focal.

\section{Resultados}

\section{Categorias elaboradas a partir dos depoimentos}

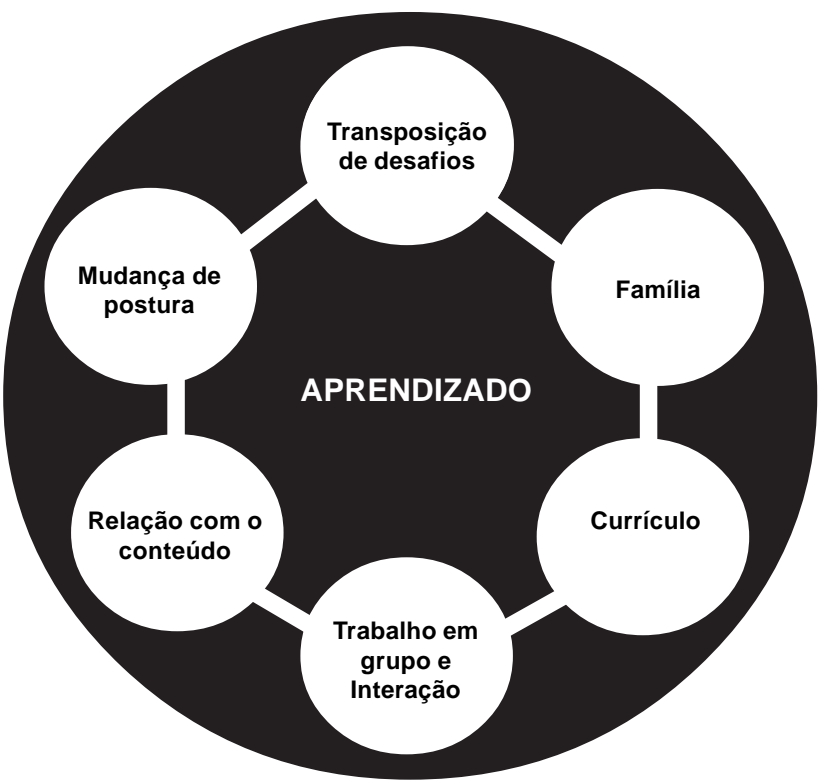

Diagrama 1. Agrupamento, por categorias de identificação, das percepções dos educandos.

\section{Aprendizado}

Os depoimentos evidenciaram um sentido ampliado de aprendizado por parte dos educandos. Esse aprendizado não é determinado unicamente pela aquisição de informações específicas, mas também em articulação com outras percepções dos educandos e do educador. A categoria "aprendizado" é, portanto, o suporte básico para as demais, exemplificado no seguinte trecho de depoimento:

"Esse trabalho pra mim foi muito importante porque eu prossegui para aprender mais, trabalhar também no coletivo, isso é muito importante, pra qualquer um de nós ser humano e também são temas também que tão ligados ao dia-a-dia nosso, na nossa vida né?" (M. $4^{\circ}$ período - Ensino Fundamental) 
Moreira, A. F.; Ferreira, L. A. G.

O aprender foi entendido sob muitas formas distintas. Alguns educandos falam de um aprendizado que se articula com as relações interpessoais e com o trabalho em grupo:

"O bom desse trabalho é que eu tive mais conhecimento sobre a doença "daltonismo" que eu não sabia que existia, e passei conhecer pessoas também daltônicas, fiquei curiosa para saber por que eu acho diferente a pessoa enxergar alguns tipos de cores diferentes do que eu, não imaginava que existia isso. E também pelo trabalho em grupo que eu tive. Tinha pessoas que eu nem tinha amizade direito e passei a conhecer também através do trabalho, e eu tive conbecimento né? Mais, e também sobre a amizade, foi bom!” (K. $2^{\circ}$ período - Ensino Médio)

Alguns educandos manifestam o interesse de compartilhar com a família as experiências vividas nos Seminários, e isso qualifica um aprendizado pessoal que será compartilhado:

'Foi muito gratificante porque a mulher lá em casa mesmo né? Do câncer de mama e através dessas pesquisas né? Que a gente andou fazendo, agora eu sei passar a informação pra ela, entendeu? E sei a qualidade que tem né? Da gente saber estas coisas todas e ta passando essa "informação", foi muito legal." (D. 2 o período Ensino Médio)

Ao longo do projeto, surgem desafios, tais como: o trabalho com diferentes mídias, a necessidade da exposição oral para um grupo maior, a convivência interna com o grupo, as dificuldades no trabalho com o conteúdo específico, que podem limitar os avanços da pesquisa ou, até mesmo, torná-la inviável. Entretanto, percebe-se que alguns estudantes manifestam uma postura crítica acerca de certo comportamento, o que possibilitou a caracterização de uma forma de aprendizado voltada para uma mudança de postura e transposição de desafios:

"Eu gostei muito do trabalho que a gente fezporque aprendi agora sobre alimentação, até em casa "tou" controlando agora o sal, tão reclamando comigo que a minha comida "ta" sem gosto, mas éporque eu aprendi muito com esse trabalho e foi muito bom para mim também e até o açucar que eu gosto muito de doce, aprendi que eu não devo comer muito doce." (V. $1^{\circ}$ período 2 - Ensino Médio)

Logo, considera-se a existência do elemento "aprendizado" em um sentido mais amplo, como pano de fundo da construção das categorias propostas neste artigo.

\section{Relação com o conteúdo}

Os conteúdos específicos de Ciências e Biologia são mencionados como uma expressão direta nas falas dos educandos ou como manifestação difusa de um 'sentimento' de aprendizado, conforme se pode observar nos relatos a seguir.

"[...] o trabalho de menopausa teve pra mim uma suma importância porque eu descobri os nomes das várias células, vários hormônios, várias glândulas que eu não sabia, na verdade eu não sabia nada do corpo humano [...] aprendendo vários nomes na menopausa que permitiu ajudar minha mãe e várias pessoas ao meu 
Abordagem temática e contextos de vida ...

redor que passam por este estágio, acho que isso foi a importância da menopausa pra mim." (C. $1^{\circ}$ período 1 - Ensino Médio)

'[...] agora depois desse trabalho eu estou apto a dar vários esclarecimentos para aquelas pessoas que às vezes tem alguma duivida [...] to levando uma bagagem cheia de conhecimento." (A. $2^{\circ}$ período - Ensino Médio)

\section{Transposição de desafios}

O desenrolar da prática implicou o afloramento de dificuldades individuais e coletivas, que compuseram um cenário de desafios a serem transpostos. A superação ocorre no envolvimento e no desenvolvimento da pesquisa:

"[...] pra mim foi a coisa mais difícil, foi a etapa pior da minha vida [...] valeu a pena porque eu descobri tudo sobre a doença que eu tenho, então foi bom." (I. $1^{\circ}$ período 2 - Ensino Médio)

Dialogando pela primeira vez com essa prática, a educanda demonstrou, no início do processo, um nível elevado de rejeição aos Seminários. As dificuldades ficavam mais evidentes diante da necessidade de se utilizarem recursos de informática. Aos poucos, a convivência com os colegas, o acompanhamento realizado pelo educador durante a pesquisa, uma melhor compreensão pessoal da proposta, permitiram uma abertura à negociação, que favoreceu a superação desses desafios. As falas seguintes sinalizam a superação de desafios por parte de outros educandos, como, por exemplo, a dificuldade de falar em público:

"Primeiro a oportunidade, de aprender, né?, de aprender detalbadamente, mais a fundo sobre um assunto, né. A oportunidade de explanar sobre um assunto, a gente falar para mais pessoas e falar em público, de treinar pro futuro [...].” (A. $1^{\circ}$ Período 2 - Ensino Médio)

"[...] no ano que vem quero melhorar porque eu fiquei com muita vergonba, tremendo muito, quase desmaiei [...].” (D. $4^{\circ}$ período - Ensino Fundamental)

'[...] foi bom porque en aprendi a lidar com o grupo! Falar em público e é isso." (F. $2^{\circ}$ período - Ensino Médio)

\section{Trabalho em grupo e interação}

A complexidade do trabalho em grupo, a estreita relação entre pessoas e suas necessidades individuais permitiram o desenvolvimento de um projeto em que os resultados não estão focalizados em um único membro, mas, sim, em uma interação dos participantes do grupo. Isto pressupõe adaptações e conflitos interpessoais.

"Negociar é criar relações sociais [...]. Negociar de maneira autêntica é reunir os meios para agir, partindo-se das informações possuídas por cada um para encontrar soluções complementares, como para criar situações novas" (VENTURA, 2001, p. 128). Em uma busca pela negociação e o diálogo, valores sociais e sentimentais também são resgatados, agregando valor à identidade do grupo: 
Moreira, A. F.; Ferreira, L. A. G.

"[...] o grupo no início teve uma desunião, [...] no final foi impressionante como todo mundo quis se interessar e quis dar o melhor pro trabalho." (A. $2^{\circ}$ período - Ensino Médio)

"[...] a gente conheceu mais o grupo, igual eu e a E. a gente mal se cumprimentava né? Durante este trabalho a gente pegou a se falar mais, a gente ta mais unida." (C. $4^{\circ}$ período - Ensino Fundamental)

O processo vivenciado pelos educandos permitiu ir além da experiência de aprender conceitos de Ciências e Biologia; nesse processo, foi possível estabelecer vínculos sociais que dialogam com os objetivos da prática educativa em questão:

"[...] a gente enfrentou muitos desafios [...] saber conviver mesmo com as diferenças das pessoas, dos outros, os outros componentes." (T. $2^{\circ}$ período - Ensino Médio)

'[...] nós aprendemos muita coisa [...] com o trabalho dos outros alunos. [...] vendo que as pessoas também estão gostando, estão interessadas, estão argumentando sobre o trabalho é muito satisfatório." (W. $1^{\circ}$ período 2 - Ensino Médio)

A constituição de um ambiente de diálogo entre os educandos permitiu um reconhecimento do esforço pela pesquisa e o desejo de fazer o melhor diante de todas as dificuldades inerentes a esse público. É possível reconhecer um sentimento de êxito que se associa a um crescimento da autoestima.

\section{Mudança de postura}

De posse da informação e das contribuições coletivas, os educandos foram capazes de se autoavaliarem e reconstruírem significados pessoais no diálogo com o conhecimento produzido durante a pesquisa.

"[...] eu quando comecei a fazer [...] nem queria, nem me interessava [...] pesquisando en descobri [...] que en vou ser uma doadora e vou passar isso adiante." (P. $3^{\circ}$ período - Ensino Fundamental)

"[...] eu era contra a doação de órgãos, sempre falava pras meninas [...] eu não quero ser doadora de órgãos de jeito nenhum em bipótese alguma, quando eu morrer en quero ir com tudo meu! [...] mas hoje eu vejo que a gente tem que ajudar realmente quem precisa pra que lá pra frente [...] a pessoa possa se sentir melhor." (M. $3^{\circ}$ período - Ensino Fundamental)

\section{Família}

Outro fator relevante nas pesquisas é a articulação entre conhecimento produzido e família como possibilidade de transformação da realidade local. 
Abordagem temática e contextos de vida ...

'[...] pra mim foi interessante porque meu pai é praticamente um alcoólatra, [...] ai en soube e pude ao decorrer en estudando en pude dar uma explicação para ele do que ela faz com o corpo bumano, e [pausa] também pro meu dia-a-dia, o que ela vai fazer com o decorrer do tempo com o corpo." (A. $1^{\circ}$ período 1 - Ensino Médio)

Mesmo que ocorra uma relação do assunto pesquisado com a própria experiência de vida, em um nível superficial, essa relação pode permitir novas articulações que favorecem o aprendizado, aproximando o tema de pesquisa de uma realidade familiar, favorecendo a transposição das informações para além dos limites do ambiente escolar.

"[...] men pai fuma dentro de casa [...] men pai fuma dentro de casa, fuma ali na varanda. [...] a gente acostuma, que a criança acostuma [...] Quando eu for chegar lá em casa eu vou ver que não é isso, en já vou me sentir incomodado, já vou chegar para o men pai e falar que não!" (A2. $1^{\circ}$ período 1 - Ensino Médio)

"Pra mim foi muito importante porque o primeiro seminário foi sobre alimentação, o segundo diabetes e agora fechamos com câncer de mama. Como minha mãe agora descobrin que tem diabetes foi importante ter várias informacões sobre diabetes pra ta ajudando ela. Então pra mim foi muito importante." (E. $2^{\circ}$ período - Ensino Médio)

\section{Currículo}

Em algumas falas dos educandos, o projeto de ensino surge como uma proposta curricular relevante na prática de ensino em Ciências e Biologia, que deveria ser estendida a outras escolas e redes de ensino.

'[...] é muito bom fazer o seminário que a gente sai com uma bagagem muito grande e realmente o seminário interativo é muito importante [...] eu acredito que seria bastante interessante as escolas públicas começarem a pensar nisso também, [...] não só as escolas particulares". (C. $3^{\circ}$ período - Ensino Fundamental).

"E foi legal porque en aprendi bastante sobre Diabetes e também eu nunca tinha feito um trabalho assim, bem interessante e em grupo, porque eu estudei em escola pública e não existia esses trabalhos assim legal." (R. $1^{\circ}$ período 1 - Ensino Médio)

A prática educativa relatada neste artigo ocorre em uma escola da rede particular de ensino. As falas dos estudantes vinculam a experiência vivida nessa escola com uma característica da rede particular, em contraponto à rede pública. Em que pese essa generalização indevida dos estudantes, entendemos que as falas expressam uma percepção da experiência vivida como algo que deve, de fato, ser assumido como uma proposta curricular e, por isso, apontando o valor da prática de Seminários. 
Moreira, A. F.; Ferreira, L. A. G.

\section{A situação discursiva dos depoimentos}

O momento de apresentação pública do conhecimento produzido e organizado durante a pesquisa, o Seminário, é de culminância. Os educandos responsáveis pela apresentação são o centro das atenções, têm coisas importantes a dizer, são ouvidos e valorizados por isso. Aprendem a fazer uma apresentação multimídia, dominam uma técnica e a utilizam para se comunicar. Isto também os valoriza. Os depoimentos colhidos após as apresentações estão fortemente influenciados por esse sentimento de conquista e de autovalorização. Os educandos expressam, de forma natural e espontânea, o que emerge naquele momento. Entendemos essas falas como portadoras de elementos positivos do processo, aqueles que vêm em primeiro plano, sem reflexões de maior profundidade. A sua autenticidade e consistência se constituem a partir da análise do educador, que acompanhou todo o processo e confrontou essa experiência com os depoimentos dos estudantes. O educador não exerce, como afirma Freire, a condição de:

[...] observador imparcial, objetivo, seguro dos fatos e dos acontecimentos. Em tempo algum pude ser um observador 'acinzentadamente' imparcial, o que, porém, jamais me afastou de uma posição rigorosamente ética. Quem observa o faz de um certo ponto de vista, o que não situa o observador em erro. $O$ erro na verdade não é ter um certo ponto de vista, mas absolutizá-lo e desconhecer que, mesmo do acerto de seu ponto de vista é possível que a razão ética nem sempre esteja com ele. (FREIRE, 2003, p. 14)

Em vez de um observador imparcial, o educador que acompanhou os estudantes e realizou a pesquisa exerceu a condição de um participante do processo que reconstrói aspectos da dinâmica de produção dos Seminários a partir dos depoimentos. A visão positiva retratada por esses depoimentos converge com a reflexão sobre a ação que faz o educador sobre o processo vivido e de sua contribuição na formação dos educandos. Entretanto, o reconhecimento dessas características da situação discursiva, que caracterizamos como de culminância, implica que é preciso também criar espaços para se explicitarem contradições não superadas e aspectos negativos não revelados. Esses espaços serão constituídos no desdobramento desse estudo-piloto, no contexto de uma pesquisa em nível de mestrado.

\section{Os dados do grupo focal}

A partir dos dados registrados através do grupo focal, foi possível dialogar com alguns aspectos importantes do processo, bem como estabelecer relações de confirmação, contraponto e complemento com o conteúdo dos depoimentos espontâneos.

$\mathrm{Na}$ visão dos estudantes, o projeto é, por si mesmo, um desafio a ser transposto. Nele estão envolvidos pontos conflitantes que devem ser superados, tais como: a convivência coletiva, a exposição oral, e a sistematização de conceitos. Essa condição desafiante, já "previamente" estabelecida, e a associação da prática a uma proposta alternativa ao ensino de Ciências e Biologia podem gerar atitudes iniciais de desconfiança quanto ao desenvolvimento do projeto, conforme pode ser observado nas falas seguintes: 
Abordagem temática e contextos de vida ...

'[...] um aluno de outra sala encheu minha cabeça falando que o seminário é totalmente diferente, que no próximo ano eu veria o que era o seminário. Ai você já começa naquela coisa, você batalha o ano todo e ai chega o dia de apresentar você não consegue. O negócio é tranqülidade, não esquentar a cabeça." (J. L. $3^{\circ}$ Período - Ensino Fundamental)

"[...] Foi o primeiro seminário, [...]"o que é isso né? Fiquei surpresa [...]" (S. 20 Período Médio - 2007)

\section{a. Trabalho em grupo}

O trabalho em equipe tratado no grupo focal evidenciou um caráter divergente dos estudantes acerca dessa experiência coletiva em relação às duas turmas analisadas sob a luz do grupo focal.

Os conflitos do trabalho em grupo surgem constantemente no desenvolvimento do projeto, na medida em que os estudantes não conseguem desenvolver uma relação fundamentada no diálogo e no comprometimento com a atividade.

"[...] No men grupo faltou disponibilidade, [...] não se prontificaram em fazer o trabalho. [...] No meu grupo teve essa dificuldade, falta de companbeirismo, falta de comunicação, [...] de uma certa forma acho que o professor deveria exigir um pouco mais do trabalho em grupo, pois acho que fica muito solto [...] existe um respeito maior quando o professor cobra mais. [...] falta alguma coisa!” (S. $2^{\circ}$ Período Médio - 2007)

$\mathrm{Na}$ medida em que se configura um processo contínuo de reflexões e diálogos internos ao grupo, esse pode propiciar a superação de muitos desafios impostos pelo trabalho coletivo. Esse contexto é favorável ao estabelecimento de uma relação de acolhida baseada no diálogo e na negociação coletiva.

"[...] o pessoal foi se integrando, pegando interesse sobre aquilo e começamos a fazer o trabalho. [...] fomos a parques, fomos a museus [...]. [...] saimos do projeto com uma bagagem mais carregada, um aprendizado mais tranqüilo." (W. $3^{\circ}$ Período - Ensino Fundamental)

"[...] foi meu primeiro ano de seminário, eu não sabia nada, não sabia nem como começar o trabalho. E todas as pessoas do grupo procuraram me ajudar, esclareceram alguns pontos comigo, procuraram saber se eu estava entendendo, a gente fer. reuniões várias vezes na biblioteca para poder dividir o trabalho e procuraram saber se a gente estava dando conta. [...] O trabalho era muito grande, a gente dividia para poder ajudar. [...] Algumas pessoas que tinham mais capacidade de digitar o trabalho foram e digitaram, a gente acompanhou. [...] O que a gente apresentou lá foi esforço da gente mesmo. [...] Esse trabalho me fez conbecer pessoas melhores, às vezes a gente julga muito as pessoas pela aparência. [...] No grupo en aprendi a dar mais valor, a conhecer primeiro a pessoa para depois julgar. As 
Moreira, A. F.; Ferreira, L. A. G.

pessoas que eu julguei a primeira vista foram as pessoas que mais me ajudaram com o trabalho, e que hoje eu considero [...] e vou levar para o resto de minha vida." (K. $2^{\circ}$ Período Médio - 2007)

Mais experientes com a prática, os educandos do $2^{\circ}$ período do Ensino Médio compreendem com maior facilidade a dinâmica do trabalho em grupo como fator de destaque à elaboração do projeto, salientando aspectos positivos e negativos envolvidos no percurso de desenvolvimento do grupo em função do projeto ao longo do período. Os desafios de um trabalho coletivo são entendidos, por esses estudantes, como parte dos objetivos do projeto.

Os educandos do $3^{\circ}$ período do Ensino Fundamental fizeram poucos comentários acerca do trabalho em grupo. $\mathrm{O}$ foco dado pelos estudantes estava voltado para os mecanismos de elaboração e apresentação do seminário, deixando, em segundo plano, reflexões mais detalhadas acerca da atividade coletiva. Essa postura levanta a questão quanto aos fatores que levaram esses alunos participantes do grupo focal a não abordarem esse aspecto da dinâmica dos Seminários.

\section{b. Conteúdos conceituais e o contexto de vida}

As falas no grupo focal tornaram evidente a importância da associação dos conceitos científicos ao contexto de vida dos estudantes, de maneira a prover um aprendizado significativo, muitas vezes articulado à mudança de postura pessoal, conforme destacado nos depoimentos espontâneos.

'[...] Meu Deus! Eu queimava [...] ia lá debaixo da água, aliviava né! Colocava creme dental, um monte de coisa. Mas não podia fažer isso! Nem por um momento. Ai da última vez que en queimei eu não fiz isso! [...] Acho que foi bom, foi do dia-a-dia da gente." (M. J. $3^{\circ}$ Período - Ensino Fundamental)

'[...] antes de eu fazer o trabalbo eu realmente não tinha os cuidados necessários. Ficava no Sol, trabalhava no Sol sem dar proteção geral à pele, às vezes a gente fica muito tempo exposto ao Sol sem saber o que está acontecendo ali e o que os raios do Sol podem trazer para a gente [...]." (W. $3^{\circ}$ Período - Ensino Fundamental)

Nesse sentido, os conceitos científicos foram referenciados por meio de uma compreensão contextualizada, conforme o relato a seguir.

"Um conceito que me chamou bastante atenção e que foi falado e comentado o tempo todo em algumas apresentações que eu vi, foi a questão da divisão celular, por que a pessoa quando fala em divisão celular, ela praticamente não entende nada! [...] é mesmo o que me chamou mais atenção [...] foi descobrir realmente qual a função da divisão celular e qual a importância dela para a nossa vida. [...] Engraçado, essa divisão celular, se a gente pode analisar direito ela é uma ignição para a vida. Por que através dessa divisão é que começa a formar alguma coisa, algum ser vivo. [...] A gente carrega isso geneticamente, a célula é copiada igual a do seu pai e da sua mãe, metade de um, metade de outro, então quer dižer, mitose 
e meiose são muito importantes, [...] fiquei mais interessado ainda em conhecer mais.” (A. $2^{\circ}$ Período Médio - 2007)

As falas dos educandos das duas turmas contribuem para a visão de que o processo de aprendizagem a partir do projeto não se limita a "fazer o trabalho". É importante ressaltar o papel do grupo, da sala de aula, nas discussões e na exposição final. Esses são fatores que permitem a inserção dos educandos em um ambiente favorável à aprendizagem significativa, que não os restringe à apropriação pura de conceitos.

\section{c. Considerações sobre a prática educativa}

Os estudantes que participaram do grupo focal trouxeram argumentos que corroboraram uma avaliação positiva da prática educativa. Para eles, os seminários interativos oferecem um espaço que se estabelece como alternativa possível às aulas essencialmente expositivas.

'[...] eu nunca dava muita atenção a biologia, eu não sabia praticamente nada, [...] e através dos seminários eu pude aprender muita coisa para minha vida, até sobre a matéria biologia mesmo. Eu acho que se fosse dado pelo professor, se ele escrevesse no quadro, passasse folhas, discutir até na sala mesmo, acho que eu não iria aprender tanto como eu aprendi no seminário. Por que no seminário não foi o professor que deu uma aula, fui eu que, nós todos que procuramos correr atrás, pra poder montar aquele seminário.” (K. $2^{\circ}$ Período Médio - 2007)

As experiências com o projeto apontam para a ampliação das possibilidades de aprendizado, bem como o alcance dos saberes escolarizados para além dos limites da escola, ocupando, enfim, locais e funções significativas para a vida desse sujeito.

"[...] é interessante que esse projeto da escola porque coloca os alunos em contato com um universo diferente, os coloca em contato com pessoas diferentes, com situações diferenciadas que são situações que vamos ter que lidar no mundo lá fora, com a realidade lá de fora, que é o falar em público, o saber se organizar, todo esse processo né? [...] tem gente que ficou completamente nervoso, mas foi lá e fez, algumas pessoas não deram conta, mas é exatamente isso, por que você imagina numa entrevista de trabalho ou qualquer coisa parecida [...] as relações humanas são complicadas né?, e a escola pensar dessa maneira é muito bom, é muito importante, a escola não está alienada em só formar o aluno no ensino médio, no ensino fundamental com um "diplominha" e pronto, acho bacana esse pensamento amplo, eu gosto muito, acho isso muito positivo." (C. $3^{\circ}$ Período - Ensino Fundamental)

Por meio da prática vivenciada, os estudantes são também estimulados a assumirem o papel de sujeitos curiosos, de participantes do ato de conhecer, pois somente a partir de uma educação de pergunta é que se pode estimular e reforçar a curiosidade (AULER; DALMOLIN; FENALTI, 2009). Os educandos aproximam-se do conhecimento científico, possuem acesso aos recursos tecnológicos, desenvolvem habilidades de comunicação, interpretação e articulação do conhecimento científico e da realidade. 
Moreira, A. F.; Ferreira, L. A. G.

Nesse conjunto, o sentimento de aprendizado manifestado pelos estudantes se refere à oportunidade de se relacionarem de forma mais aproximada e crítica com seus contextos de vida. $\mathrm{O}$ valor dado ao aprendizado vincula-se à autogestão desse saber significativo e contextualizado.

\section{Conclusão}

Não se pretende afirmar, com base nas percepções dos educandos, que a prática educativa em questão é inovadora. No entanto ela concretiza elementos que parecem criar um ambiente de aprendizagem para o estudante da EJA. Que elementos seriam esses? A proposição de temas de pesquisa que articulam conceitos de Ciências e Biologia com os contextos de vida dos estudantes, e a problematização inicial desses temas, buscando justamente e deliberadamente o diálogo com esses contextos e, por conseguinte, com os saberes prévios dos estudantes, valorizando a experiência que eles trazem para a escola; e a estruturação e desenvolvimento do currículo de Ciências e Biologia em torno da preparação e apresentação dos Seminários. Esse processo começa com o início do período letivo e culmina na apresentação pública dos resultados das pesquisas, os Seminários Interativos, nos meses de agosto e setembro. Corre-se o risco de se terem produções pobres, não obstante o acompanhamento feito pelo educador para dinamizar o processo, vencer as dificuldades e desafios do trabalho em grupo, do estudo bibliográfico, do entendimento dos conceitos.

No dia do Seminário, o protagonismo é todo dos estudantes. É o compartilhar do conhecimento produzido. Nem sempre há profundidade, nem sempre o senso comum é ultrapassado, mas, nesse momento, os estudantes saem da margem e estão no centro. O momento dos Seminários é de fato interativo. Os responsáveis pela apresentação e os demais participantes da turma efetivamente dialogam em torno do tema, tendo em mãos o texto produzido pelos grupos durante a pesquisa. Predominam a riqueza e a diversidade de fontes e formas de apresentação.

Se a problematização inicial busca fazer o tema gerador, assim como o acompanhamento sistemático do educador, o Seminário também cumpre esse papel e estabelece uma agenda de organização, sistematização e aprofundamento de conhecimentos, que é cumprida na revisão conceitual realizada pelo educador, juntamente com os educandos, e na avaliação, realizada em dupla, sobre os conceitos trabalhados no Seminário.

Os Seminários Interativos tiram o educando da margem e o colocam no centro da produção e socialização dos conhecimentos, enfrentando os riscos de um empobrecimento do que é produzido, da não-ultrapassagem do senso comum, mas apostando: na interatividade, no trabalho com diferentes fontes de informação e em grupo, no diálogo proporcionado ao longo de todo o processo, e no estabelecimento de uma agenda de organização e aprofundamento de conhecimentos, que são significativos porque foram resultado de uma busca sistemática de articulação com os contextos de vida dos educandos.

Concluímos afirmando, juntamente com Britto (2008), que essa educação constitui a possibilidade - pela convivência com a contínua produção e a circulação do conhecimento de uma pessoa e de um coletivo pensarem suas vidas, seus modos de ser e estar no mundo, enfim, de viver e fazer a condição humana. 
Abordagem temática e contextos de vida ...

\section{Referências}

AULER, D.; DALMOLIN, M. T. A.; FENALTI, S. V. Abordagem temática: a natureza dos temas em Freire e no enfoque CTS. Alexandria: Revista de Educação em Ciência e Tecnologia, Florianópolis, v. 2, n. 1, p. 67-84, 2009.

BORDENAVE, J. D.; PEREIRA, A. M. Estratégias de ensino e aprendizagem. 24. ed. Rio de Janeiro: Vozes, 2000.

BRITTO, L. P. L. Educação de adultos: formação x pragmatismo. REVEJ@: Revista de Educação de Jovens e Adultos, Belo Horizonte, v. 2, n. 2, p. 53-60, 2008. Disponível em: $<$ http://www.reveja.com.br/sites/default/files/REVEJ@_3_Percival.pdf>. Acesso em: 24 dez. 2010.

CARRANO, P. Educação de jovens e adultos e juventude: o desafio de compreender os sentidos da presença dos jovens na escola da "segunda chance". REVEJ@: Revista de Educação de Jovens e Adultos, Belo Horizonte, v. 1, n. 0, p. 55-67, 2007. Disponível em: $<$ http://www.reveja.com.br/sites/default/files/REVEJ@_0_PauloCarrano.pdf>. Acesso em: 22 dez. 2010.

DAYRELL, J. A escola como espaço sócio-cultural. In: (Org.). Múltiplos olhares sobre a educação e cultura. Belo Horizonte: UFMG, 1996. p. 136-161.

DI PIERRO, M. C.; JOIA, O.; RIBEIRO, V. M. Visões da educação de jovens e adultos no Brasil. Cadernos CEDES, Campinas, v. 21, n. 55, p. 58-77, 2001. Disponível em: $<$ http://www.scielo.br/scielo.php?script=sci_arttext\&pid=S0101-32622001000300005\&lng $=$ pt\&nrm=iso $>$. Acesso em: 23 abr. 2007.

FONSECA, N. A.; MOURA, D. G.; VENTURA, P. C. S. Os projetos de trabalho e suas possibilidades na aprendizagem significativa: relato de uma experiência. Educação

Tecnológica, Belo Horizonte, v. 9, n. 1, p. 13-20, 2004.

FREIRE, P. Pedagogia da autonomia: saberes necessários à prática docente. Rio de Janeiro: Paz e Terra, 2003.

Pedagogia do oprimido. 34. ed. Rio de Janeiro: Paz e Terra, 2002.

GIBBS, A. Focus groups. Social Research Update, Guildford, n. 19, 1997. Disponível em: $<$ http://sru.soc.surrey.ac.uk/SRU19.html>. Acesso em: 25 maio 2008.

HADDAD, S.; DI PIERRO, M. C. Aprendizagem de jovens e adultos: avaliação da década da educação para todos. São Paulo em Perspectiva, São Paulo, v. 14, n. 1, p. 29-40, 2000. Disponível em: <http://www.scielo.br/scielo.php?script=sci_arttext\&pid=S010288392000000100005\&lng=pt\&nrm=iso > . Acesso em: 22 abr. 2007.

HANSEN, M; PINHEIRO, T. Projetos de trabalho e o ensino de ciências. In: ENCONTRO NACIONAL DE PESQUISA EM EDUCAÇÃO EM CIÊNCIAS, 5., 2005, Bauru. Anais... Bauru: ABRAPEC, 2005. 1 cd-rom.

KIND, L. Notas para trabalho com a técnica de grupos focais. Psicologia em Revista, Belo Horizonte, v. 10, n. 15, p. 124-136, 2004. 
Moreira, A. F.; Ferreira, L. A. G.

LABURÚ, C. E.; CARVALHO, M. Educação científica: controvérsias construtivistas e pluralismo metodológico. Londrina: Editora Eduel, 2005.

MENEZES, P. Tradição e inovação no ensino de física: grupos colaborativos de professores dando estabilidade a mudanças. 2003. 135f. Dissertação (Mestrado em Educação) - Universidade Federal de Minas Gerais, Belo Horizonte, 2003.

OLIVEIRA, M. K. Jovens e adultos como sujeitos de conhecimento e aprendizagem. Revista Brasileira de Educação, Rio de Janeiro, n. 12, p. 59-73, 1999. Disponível em: $<$ http://www.anped.org.br/rbe/rbe/rbe.htm>. Acesso em: 10 set. 2006.

PRATA, R; MARTINS, I. Ensino de ciências e educação de jovens e adultos: pela necessidade do diálogo entre campos e práticas. In: ENCONTRO NACIONAL DE PESQUISA EM EDUCAÇÃO EM CIÊNCIAS, 5., 2005, Bauru. Anais... Bauru: ABRAPEC, 2005. 1 cd-rom.

SANTOS, G. L. Educação ainda que tardia: a exclusão da escola e a reinserção de adultos das camadas populares em um programa de EJA. Revista Brasileira de Educação, Rio de Janeiro, n. 24, p. 107-125, 2003. Disponível em: < http://www.scielo.br/pdf/rbedu/n24/ n24a09.pdf>. Acesso em: 8 mar. 2009.

SANTOS, W. L. P. Educação científica na perspectiva de letramento como prática social: funções, princípios e desafios. Revista Brasileira de Educação, Rio de Janeiro, v. 12, n. 36, p. 474-492, 2007. Disponível em: <http://www.scielo.br/pdf/rbedu/v12n36/ a07v1236.pdf >. Acesso em: 9 jun. 2008.

SOUZA, V; JUSTI, R. O ensino de ciências e seus desafios humanos e científicos: fronteiras entre o saber e o fazer científico. In: ENCONTRO NACIONAL DE PESQUISA EM EDUCAÇÃO EM CIÊNCIAS, 5., 2005, Bauru. Anais... Bauru: ABRAPEC, 2005. 1 cd-rom.

TEIXEIRA, P. A educação científica sob a perspectiva da pedagogia histórico-crítica e do movimento C.T.S no ensino de ciências. Ciência \& Educação, Bauru, v. 9, n. 2, p. 177-190, 2003. Disponível em: <http://www.scielo.br/scielo.php?script=sci_pdf\&pid= S1516-73132003000200003\&lng=en\&nrm=iso\&tlng=pt >. Acesso em: 21 abr. 2007.

VENTURA, P. C. S. La négociation entre le concepteur, les objets et le public dans les musées techniques et les salons professionnels. 2001. 223f. Tese (Doutorado) Université de Bourgogne, Dijon, 2001.

Artigo recebido em 18/11/2010. Aceito em 27/01/2011. 